\title{
Assessment of indoor air quality in comparison using air conditioning and fan system in printing premise
}

\author{
Nazirah Ramlan ${ }^{1}$, Siti Nurhalimatul Husna Ahmad ${ }^{1}$, Eeydzah Aminuddin ${ }^{2}$, Hazrul Abdul Hamid ${ }^{1}$, Siti Khalijah \\ Yaman $^{1}$ and $A b d$ Halid Abdullah ${ }^{1}$ \\ ${ }^{1}$ Faculty of Civil and Environmental Engineering, Universiti Tun Hussein Onn Malaysia, 86400 Batu Pahat, Malaysia \\ ${ }^{2}$ Faculty of Civil Engineering, Universiti Teknologi Malaysia, 81310 Johor Bahru, Johor, Malaysia
}

\begin{abstract}
Printers contribute to various emissions consist with chemical contaminants. High concentration of the particulate matter can cause serious health problems. This study focuses on the indoor air quality in printing premise unit in Universiti Tun Hussein Onn, Malaysia. Field testing involving air sampling methods were taken from 900 hours to 1600 hours, for every 30 minutes using physical measurement which is Multi-Channel Air Quality Monitor (YESAIR), E-Sampler and Ozone Meter. Air sampling was recorded based on one sampling point and most suitable point for production. A comparison based on different ventilation using fan and air-conditioning were also taken and results is being compared based on OSHA and NIOSH standards. Besides that, the statistical analysis is being conducted in order to predict the effect on number of printers. From the result, the $\mathrm{O}_{3}$ concentrations show, $10 \%$ reduced for printing premise using fan ventilation compared to air-conditioning but remain the same value for PM2.5. The concentration of $\mathrm{O}_{3}$ increased when the number of printers decreased, while the concentration of PM2.5 increased the increase of printers number. Overall, the use of fan in printing premise is more suggested since the level is slightly lower than the printing premise using air-conditioning.
\end{abstract}

\section{Introduction}

Air is a precious resource for all humans and living things. Indoor air quality is significant to the human since most of the time spent in the buildings. According to Mohd Dzulkifli S.N. et al. (2014), poor level of indoor air quality since indoor air pollutants is not easy to dilute compared to outdoor pollutants. There are many factors that damage the air quality from rapid development such as increasing number of vehicles, factory's waste, dusts from construction works, industrial sources and materials use for building. Some of the electrical components used in the building are computers, printers, copiers and other electronic equipment [1]. The Environmental Protection Agency (EPA) defines Indoor Air Quality (IAQ) as the temperature, humidity, ventilation and chemical or biological contaminants of the air inside a building [2].

Nowadays, printing services are very popular and it has been widely used in Malaysia. It became one of the most important services for people in their daily lives. Printing services have been used by many people include the workers and students from school or university. The services provided by printing premises are photocopy, scanning, binding and lamination, booklet and nametag. It is a well-known the fact that in the printing process hazardous substances occur in the air, threatening human health [3]. There are few potential source from indoor pollutants from printers [4,5] whereby the main pollutants identified are from volatile organic compound [6], ozone [7] and fine particles [8]. One of important factor in indoor environment is fine particle due to the effect to health and also for how inhabitants perceive the environment [9].

According to Kim et al. (2008), a fuser or also called as a toner fixation unit released a particles and addition to it, different condition of fuser from the operation of printer may contributed to different size of particle distributions. Damanhuri et. al., 2015 report that the emission rates of compound are significantly influence by printer speed and the coverage of printing job that affected the quality of indoor environment.

Kiurski, J. S. et al., 2013 added that the printer that were used in printing premises for printing services is one of the items that emit the air pollution and it will lead to poor air quality. Some illnesses such as cough, headaches, eyes irritation or dizziness were caused by poor air quality. In a report by World Resources Institute 1998), indoor air pollution has been recognize as a global environmental problem. These pollutants include airborne particles and particulate matter such as gases, toxic chemicals and volatile organic compounds (VOCs). Based on a studies by U.S. Environmental Protection Agency (EPA), there is a cases where level of pollutants for indoor environment are higher than outdoor environment. EPA is concern about particles

*Corresponding author: khalijah@uthm.edu.my 
that are 10 micrometers in diameter which are "inhalable course particles" and below 2.5 micrometers which are "fine particles". Due to Fisk WJ (1987), 'buildings were assumed to shelter occupants from outdoor pollutants and little thought was given to pollutants generated or trapped indoors'. Table 1 shows the list of indoor air contaminants and acceptable limits based on ASHRAE standard 62-2004 and DOSH.

Therefore, this paper investigates the indoor air quality in printing premises. The investigation is directly to monitor the main potential pollutants with is the VOCs Ozone and fine particle. Besides that the IAQ parameters such as the temperature and relative humidity were also being recorded.

\section{Analysis method}

\subsection{Mapping}

Figure 1 shows the position of the printers inside the premise. The arrangement of furniture is being organized based on one cubicle and $\mathrm{u}$-shape desk.

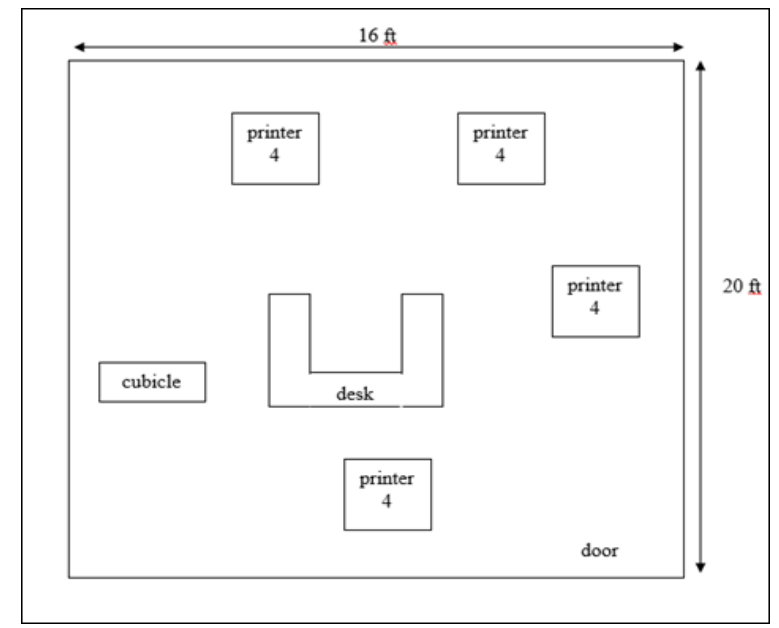

Fig. 1. Position of printer in the premise.

Table 1. List of indoor air contaminants and the acceptable limits

\begin{tabular}{|l|c|c|c|}
\hline \multirow{2}{*}{ Indoor Air Contaminant } & \multicolumn{3}{|c|}{ Acceptable limits } \\
\cline { 2 - 4 } & $\mathbf{p p m}$ & $\mathbf{m g} / \mathbf{m}^{\mathbf{3}}$ & $\mathbf{c f u} / \mathbf{m}^{\mathbf{3}}$ \\
\hline Chemical contaminants & 10 & - & - \\
a. Carbon monoxide & 0.1 & - & - \\
b. Formaldehyde & 0.05 & - & - \\
c. Ozone & - & 0.15 & - \\
d. Respirable particulates \\
e. Total volatile organic \\
$\quad$ compounds (TVOC) & 3 & - & - \\
$\quad$ & & & \\
$\quad \begin{array}{l}\text { Biological contaminants } \\
\text { a. Total bacterial counts } \\
\text { b. Total fungal counts }\end{array}$ & - & - & $500^{*}$ \\
\hline $\begin{array}{l}\text { Ventilation performance } \\
\text { indicator }\end{array}$ & - & - & $1000^{*}$ \\
a. Carbon dioxide & $\mathrm{C} 1000$ & - & - \\
\hline
\end{tabular}

\subsection{Sampling}

The space for printing premise is about $16 \mathrm{ft}$ by $20 \mathrm{ft}$ with closed door as to control the contaminants value. The location situated in printing premises unit in University of Tun Hussein Onn Malaysia. The field testing involve are from air sampling methods which were taken from 0900 hours to 1600 hours, for every 30 minutes using physical measurement which is Multi-Channel Air Quality Monitor (YESAIR), E-Sampler and Ozone Meter. The room temperature ranging in between $26^{\circ} \mathrm{C}$ $28^{\circ} \mathrm{C}$ with relative humidity in the range of 50-60\%.

\subsection{Descriptive analysis}

The descriptive statistics parameters that were used for analyses the data collected are the number of data, mean, mode, median, maximum number and minimum number. From the descriptive statistics, the simpler interpretation of the data can be obtained and the data was presented in a more meaningful way. In order to determine the outliers of $\mathrm{O}_{3}$ and $\mathrm{PM}_{2.5}$, the box plot was used in the analysis. Outlier is an observation point that is distant from other observation. From the box plot obtained, the skewness of data can be obtained.

\subsection{Correlation analysis}

In order to achieve the objective for this research, the correlation analysis method was used. The correlation analysis was used to describe the linear relationship between two continuous variables which is between the numbers of printers operated with the level of contamination indoor air. The correlation measures the strength and direction of the linear relationship. This method can show whether and how strongly pairs of variables are related.

\section{Result and discussion}

\subsection{Descriptive statistics}

The collected data were analysed and the values of mean, mode, and median were determined and tabulated in the Table 2. The results show that the mean of ground level ozone and $\mathrm{PM}_{2.5}$ are still comply the standard which is 0.05 and $150 \mu \mathrm{g} / \mathrm{m}^{3}$ respectively. For comparison purposes, the mean of $\mathrm{O}_{3}$ for printing premise using air-conditioning is slightly high compared to printing premises using fan and based on the value of mean, mode and median, the distribution of monitoring records are almost symmetry or normally distributed.

Based on the monitoring records, the data of $\mathrm{O}_{3}$ and $\mathrm{PM}_{2.5}$ for air-conditioning and fan have been transfer into boxplot. From the information that was obtained from the boxplot, the skewness of the data can be known. The boxplot of the data can be seen in Figure 2, Figure 3, and Figure 4. Both boxplot for $\mathrm{O}_{3}$ and $\mathrm{PM}_{2.5}$ are negatively skewed and positively skewed respectively. Negatively skewed shows that the most frequent data to occur indicate a larger value and as positively skewed means 
that the most frequent data that were collected are smaller than median.

Table 2. Descriptive statistics parameters

\begin{tabular}{|l|c|c|c|c|}
\hline & \multicolumn{2}{|c|}{ Air-conditioning } & \multicolumn{2}{c|}{ Fan } \\
\hline & $\begin{array}{c}\mathbf{O}_{\mathbf{3}} \\
(\mathbf{p p m})\end{array}$ & $\begin{array}{c}\mathbf{P M}_{\mathbf{2 5}} \\
\left(\boldsymbol{\mu g} / \mathbf{m}^{\mathbf{3}}\right)\end{array}$ & $\mathbf{O}_{\mathbf{3}}(\mathbf{p p m})$ & $\begin{array}{c}\mathbf{P M}_{\mathbf{2 . 5}} \\
\left(\boldsymbol{\mu g} / \mathbf{m}^{\mathbf{3}}\right)\end{array}$ \\
\hline $\mathrm{N}$ & 141 & 141 & 141 & 141 \\
\hline Mean & 0.020 & 11 & 0.019 & 11 \\
\hline Mode & 0.021 & 8 & 0.020 & 7 \\
\hline Median & 0.020 & 9 & 0.020 & 7 \\
\hline Maximum & 0.023 & 169 & 0.022 & 106 \\
\hline Minimum & 0.012 & 1 & 0.015 & 2 \\
\hline
\end{tabular}

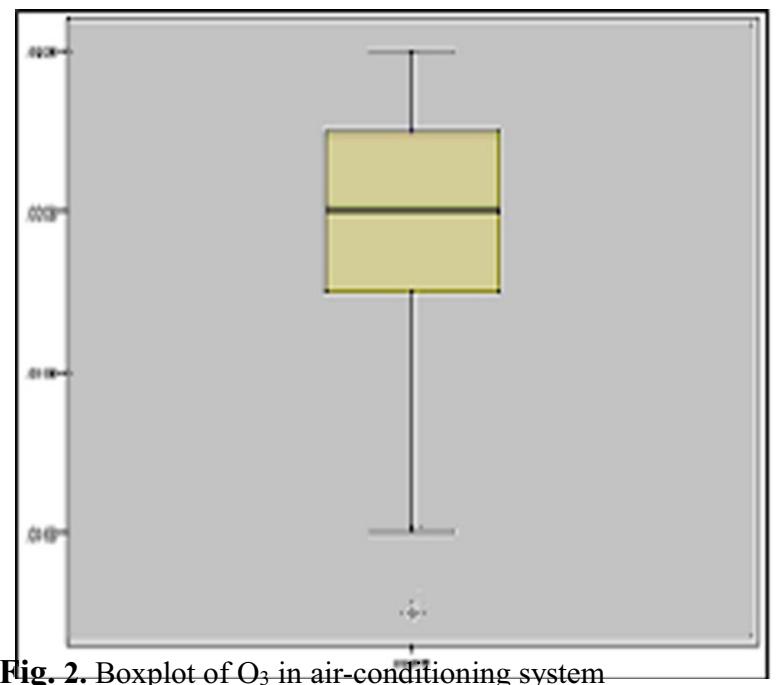

Fig. 2. Boxplot of $\mathrm{O}_{3}$ in air-conditioning system

\subsection{Correlation analysis}

From the data collected, the relationships between the numbers of printers operated with the level of contamination indoor air $\mathrm{PM}_{2.5}$ and $\mathrm{O}_{3}$ were analysed. The correlation analysis method was used in this study in order to analyse the relationship. Table 3 shows the correlation coefficient for concentration of $\mathrm{O}_{3}$ and $\mathrm{PM}_{2.5}$.

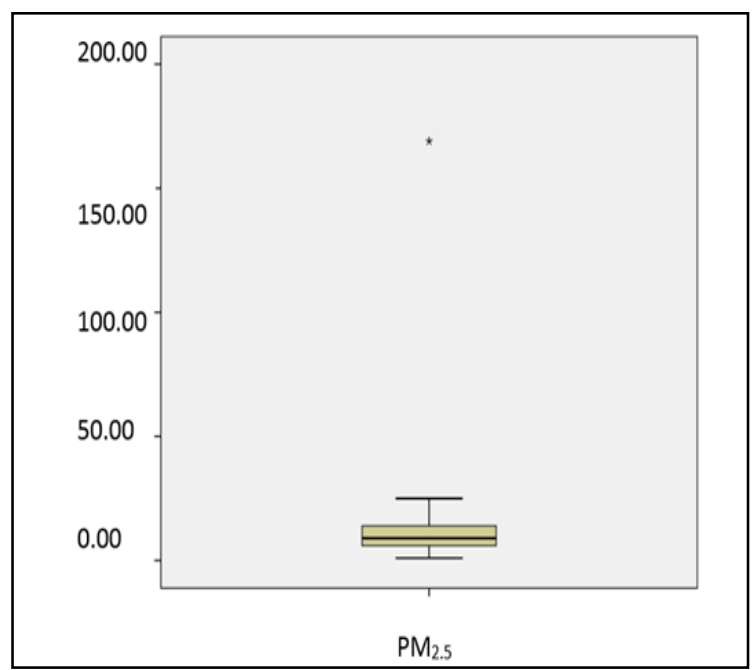

Fig. 3. Boxplot of $\mathrm{O}_{3}$ in fan system

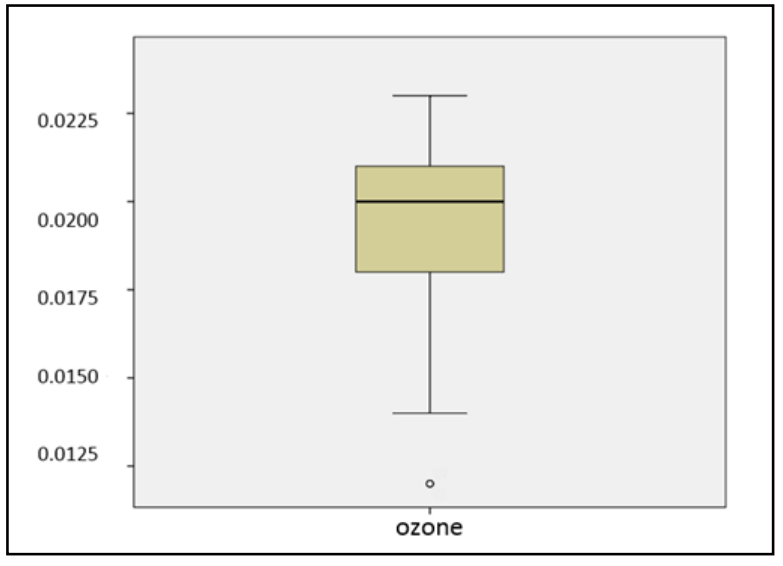

Fig. 4. Boxplot of $\mathrm{PM}_{2.5}$ in air-conditioning system

Table 3. Correlation coefficient of $\mathrm{O}_{3}$ And $\mathrm{PM}_{2.5}$

\begin{tabular}{|c|c|c|}
\hline Parameters & Correlation of air-cond. & Correlation of fan \\
\hline $\mathrm{O}_{3}$ & -0.41 & -0.18 \\
\hline $\mathrm{PM}_{2.5}$ & 0.07 & -0.09 \\
\hline
\end{tabular}

Based on the Table 3, the correlation coefficient of $\mathrm{O}_{3}$ in air-conditioning and fan system is -0.41 and -0.18 while correlation coefficient of $\mathrm{PM}_{2.5}$ is 0.07 and -0.09 respectively. The relationship for $\mathrm{O}_{3}$ is known as the negative relationship while the relationship for $\mathrm{PM}_{2.5}$ is known as positive relationship. Otherwise, the relationship of $\mathrm{PM}_{2.5}$ for fan is known as the negative relationship. The strength of the correlation can be analyzed based on the guide that Evans (1996) suggests that were tabulated in the Table 4.

Table 4. Correlation guideline: absolute value of pearson's coefficient, $\mathrm{R}$

\begin{tabular}{|c|c|}
\hline Strength & Coefficient, $\mathbf{r}$ \\
\hline Very weak & $0.0-0.19$ \\
\hline Weak & $0.2-0.39$ \\
\hline Moderate & $0.4-0.59$ \\
\hline Strong & $0.6-0.79$ \\
\hline Very strong & $0.8-1.0$ \\
\hline
\end{tabular}

From the Table 4, the result of correlation of $\mathrm{O}_{3}$ was in the range of $0.4<\mathrm{r}<0.59$ which means the correlations are moderate. Meanwhile, the correlation coefficient of $\mathrm{PM}_{2.5}$ was in the range of $0.0<\mathrm{r}<0.19$ which means very weak. From the result, the concentration of $\mathrm{O}_{3}$ increased when the number of printers decreased. Meanwhile, the concentration of $\mathrm{PM}_{2.5}$ increased when the number of printers increased. Otherwise, the result of correlation of $\mathrm{O}_{3}$ and $\mathrm{PM}_{2.5}$ are in the range of $0.0<\mathrm{r}<0.19$. This indicates that the relationship in between $\mathrm{PM}_{2.5}$ and $\mathrm{O}_{3}$ is very weak.

Based on the result from Brown et al. (1999), there are different results for contaminated indoor air when the number of printer use is different. From the recent reports, it has been identified and measured that the emissions of ultrafine particle were exist during operation of laser printers [4, 15] and copiers [16]. Further studies are needed to better understanding on the type of printer used and the types of printing activity such as fax, colour printer, copier, and scanner. 


\subsection{Graphical analysis}

Figure 5 shows the graph of $\mathrm{O}_{3}$ against time while Figure 6 shows graph of $\mathrm{PM}_{2.5}$ against time. The figure below shows the graph of $\mathrm{O}_{3}$ and $\mathrm{PM}_{2.5}$ against time for ten (10) days which are from $28^{\text {th }}$ February 2016 until $13^{\text {rd }}$ March 2016. The guidelines for both $\mathrm{O}_{3}$ that cannot be exceed which is $0.05 \mathrm{ppm}$. Meanwhile, the acceptable limit based on Department of Occupational Safety and Health (DOSH) for $\mathrm{PM}_{2.5}$ is $150 \mu \mathrm{g} / \mathrm{m}^{3}$. The critical result that was obtained for $\mathrm{O}_{3}$ is $1^{\text {st }}$ March 2016 and for $\mathrm{PM}_{2.5}$ is $3^{\text {rd }}$ March 2016. Based on the graph, the reading of $\mathrm{O}_{3}$ rose from 0.018 to $0.022 \mathrm{ppm}$ starting from 12.15 until $2.30 \mathrm{pm}$ because on that time the printers are not working or at rest condition. Meanwhile, when the printers were at rest, both contaminations were volatile in indoor air. Also the surrounding was lack of airflow from an outdoor and the air in surrounding was caught at one place. This is the critical part where both contaminant emission from printers. A by-product from printing processes of laser printers and photocopiers is ozone. The fluctuate values of ozone is depending on airflow around printer, ozone diffusion in air, or the characteristic of ozone monitor used in this study [4].

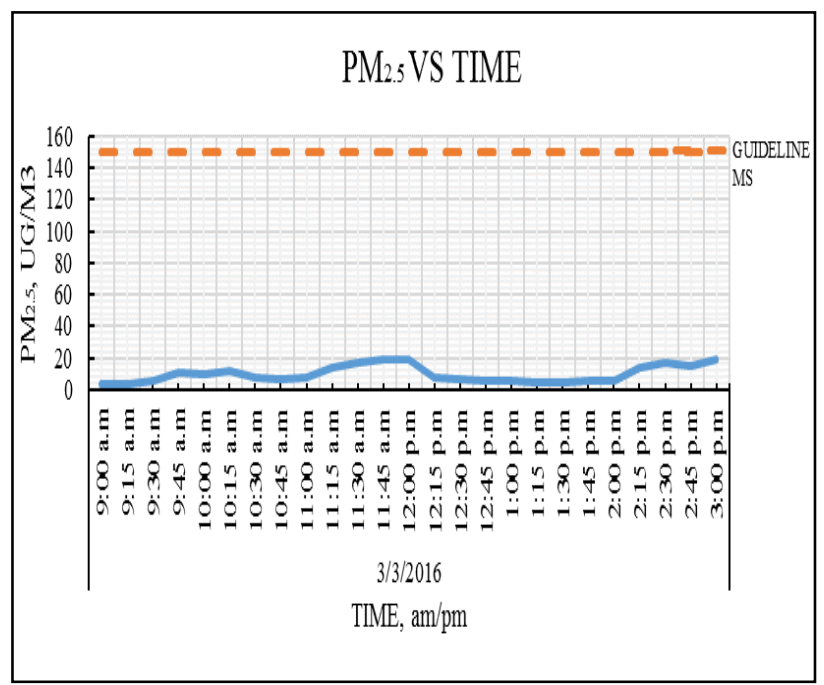

Fig. 5: Graph of $\mathrm{O}_{3}$ vs. time

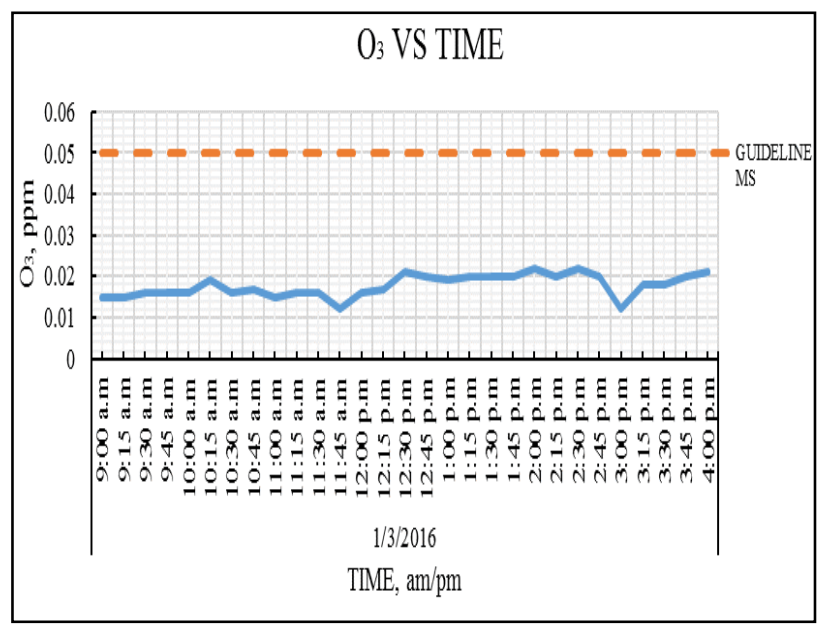

Fig. 6: Graph of $\mathrm{PM}_{2.5}$ vs time

\section{Conclusion}

Based on the discussion and the analysis, IAQ inside printing premise unit was found safe to occupants where the levels of contaminants inside the building are low. The result for air temperature, relative humidity, $\mathrm{O}_{3}$, VOCs and $\mathrm{PM}_{2.5}$ shows a positive sign for good IAQ and below DOSH standard and permissible limit by DOSH. Besides that, the relationships between numbers of printers operated with the level of contamination shows that using air-conditioning system, the relationship between the number of printers with the level of contaminate air for $\mathrm{O}_{3}$ is moderate (negative), indicated when numbers of printers operated increase, the concentration of $\mathrm{O}_{3}$ decrease. Meanwhile, the relationship for $\mathrm{PM}_{2.5}$ is weak (positive) indicated numbers of printer increases will cause increasing in concentration. Unlike $\mathrm{O}_{3}$ and $\mathrm{PM}_{2.5}$ the relationship shows a weak results when fan is applied.

The authors wish to sincerely thank the managers of the copy center whose generosity made this study possible. This investigation was made possible by Short Term Grant, U338, UTHM, Malaysia.

\section{References}

1. Jeong, H. B. \& Jang W. K., Particle Emission from Laser Printers with Different Printing Speeds. Atmospheric Environment. (2012)

2. Fiedler N., Laumbach R, Kelly-McNeil K, Lioy P., Fan Z.H., Zhang J., Ottenweller J., OhmanStrickland P., and Kipen H., Health effects of a mixture of indoor air volatile organics, their ozone oxidation products, and stress. Enviro health Perspect, 113(11):1542-8. (2005)

3. Kiurski, J. S., Marić, B. B., Aksentijević, S. M., Oros, I. B., Kecić, V. S. \& Kovačević, I.M., Indoor Air Quality Investigation from Screen Printing Industry. Renewable and Sustainable Energy Reviews (2013)

4. Kagi N., Fujii S., Horiba Y., Namiki N., Ohtani Y., Emi H., Tamura H., Kim Y.S., Indoor air quality for chemical and ultrafine particle contaminants from printers, Building and Environment, 42(5), 19491954. (2007)

5. The World's Worst Pollution Problems; assessing health risks at hazardous waste sites, Blacksmith Institute, p.9,32, 43.(2012)

6. Destaillats H., Maddalena R.L., Singer B.C., Hodgson A.T., McKone, T.E., Indoor pollutants emitted by office equipment: A review of reported data and information needs, Atmospheric Environment, 42(7), 1371-1388. (2008)

7. Wang H., He C., Morawska L., Mcgarry P., Printergenerated ultrafine particles : the role of ozone, 10th International Official Conference of the International Society of Indoor Air Quality and Climate, Brisbane, Australia. (2012)

8. Saraga D., Pateraki S., Papadopoulos A., Vasilakos C., Maggos T., Studying the indoor air quality in 
three non-residential environments of different use: A museum, a printery industry and an office. Building and Environment, 46(11), 2333-2341. (2011)

9. Gudmundsson, A., Löndahl, J., Bohgard, M., Methodology for Identifying Particle Sources in Indoor Environment. Journal of Environmental Monitoring (2007).

10. Kim, Jae Hoon, Jin Hee An, Young Soo La, Jin Su Jung, Han Mo Jeong, Suck Man Kim, Nam Gu Moon, Byung Wha Lee, Young Ho Yoon, and Young Il Choi. Journal of Industrial and Engineering Chemistry 14 (2): 194-201 (2008)

11. Damanhuri A.A.M., Leman A.M., Abdullah A.H., Hariri A., Effect of toner coverage percentage and speed of laser printer on total volatile organic compound (TVOC), Chemical Engineering Transactions, 45, 1381-1386 (2015)

12. WRI [World Research Institute]. In collaboration with the United Nations Environment Programme, the United Nations Development Programme, and the World Bank. World Resources Report 1998-99 New York: Oxford University Press. (1998)
13. Evans, J. D., Straightforward Statistics for The Behavioral Sciences. Pacific Grove, CA: Brooks/Cole Publishing (1996)

14. Brown SK. Assessment of pollutant emissions from dry-process photocopiers. Indoor Air. 9-25 (1999)

15. He, C., Morawska, L. \& Taplin, L., 2007. Particle Emission Characteristics of Office Printers. Environment Science Technology. 41(17): 60396045

16. Lee, C. W. \& Hsu, D. J., Measurements of Fine and Ultrafine Particle Formation in Photocopy Centers in Taiwan. Atmospheric Environment. 41:65986609. (2007)

17. DOSH [Department of Occupational Safety and Health], 2005. Code of Practice on Indoor Air Quality. Ministry of Human Resources Malaysia

18. EPA, 1997. An Office Building Occupant's Guide to Indoor Air Quality. Washington, DC (20460)

19. S.N. Mohd Dzulkifli, Abdullah A.H and A.M. Leman. Indoor Air Quality of Museum Building Environment in a Tropical Climate: Proposed Study. $3^{\text {rd }}$ Scientific Conference on Occupational Safety and Health. (2014) 